\title{
Personal Protective Equipment (PPE) and Its Use in COVID-19: Important Facts
}

\author{
Srijit Das ${ }^{1}$ (I) $\cdot$ Sakthiswary Rajalingham ${ }^{2}$
}

Received: 1 May 2020 / Accepted: 22 May 2020 / Published online: 28 May 2020

(C) Association of Surgeons of India 2020

Healthcare workers (HCWs) are constantly battling the Coronavirus disease 2019 (COVID-19) pandemic, and they need to wear the personal protective equipment (PPE). The PPE may be essentially required when working in an environment of free-flowing body fluids of the patients. Wearing of PPE does not and should not absolve one from distancing, no touch technique, and other precautions. In fact, a clever health care professional with a good mask, face shield, and gloves should be able to get most of the protection if the mannerism and the conduct are proper.

Any PPE should not be used without proper training or a workshop. One training in using PPE may not be good enough, as many problems may exist all the way. We think that a communication platform within the department or team is essential to address any day-to-day issues and problems related to PPE. This will prevent future complications, clarify any doubts, and allay possible anxiety among all healthcare workers.

One of the major complications is breach of PPE at work. There may be various strategies to prevent complications related to PPE. These may include (i) establishing a forum to share problems and these may include any app group, any online meetings, and face-to-face meetings in the department in order to address all issues related to PPE; (ii) developing a communication platform among other doctors and nurses to prevent several cascading problems; (iii) developing a "buddy system"- a dedicated staff or

Srijit Das

drsrijit@gmail.com

1 Department of Anatomy, Universiti Kebangsaan Malaysia Medical Centre, 56000 Cheras, Kuala Lumpur, Malaysia

2 Department of Medicine, Universiti Kebangsaan Malaysia Medical Centre, 56000 Cheras, Kuala Lumpur, Malaysia team member to observe the donning and doffing procedure and help with the procedure; and (iv) having a designated area (with enough space) for donning and doffing and shower area for the doctors and nurses working in the COVID-19 areas. Training of PPE should include how to use, how to handle breach, and when to quarantine, and prophylaxis, if breach happens. One should also address common practical problems such as what to do, if one has to consume more water or have lunch, and where and how to take care of the mask. One has to be made aware of the limitations and proper disposal of PPE.

The employers are required to take the proper size which may exactly fit and be comfortable for each employee. It is advisable to follow the guidelines of World Health Organization (WHO) which also specifies the types and also grams per square meter $\left(\mathrm{g} \mathrm{m}^{2}\right)$ [1].

There are three types of masks, i.e., single-use mask (single layer), surgical mask, and pollution mask (respirators) which prevent $90 \%$ of virus-sized particles [2]. The respirators may include ratings such as N95, KN95, FFP1, FFp2, and FFP3. The N95 mask may prevent particles up to the size of $0.3 \mu \mathrm{m}$ [2]. The mask standards vary according to each country, and the cost-effectiveness also depends on conducted trials [3].

Last but not the least, we feel that any individual with history contact dermatitis or any allergic disease should be advised to take antihistamine. The PPE materials could also be tested regularly for any hypersensitivity. 


\section{Compliance with Ethical Standards}

Conflict of Interest The authors declare that they have no conflict of interest.

\section{References}

1. https://www.who.int/medical_devices/WHO_coverall_comparison table.pdf?ua=1. Accessed 12 May 2020
2. Robertson P. Comparison of mask standards, ratings, and filtration effectiveness. https://smartairfilters.com/en/blog/comparison-maskstandards-rating-effectiveness/. Accessed on 12 May 2020

3. Mukerji S, MacIntyre CR, Seale H, Wang Q, Yang P, Wang X, Newall AT (2017) Cost-effectiveness analysis of N95 respirators and medical masks to protect healthcare workers in China from respiratory infections. BMC Infect Dis 17:464. https://doi.org/10. 1186/s12879-017-2564-9

Publisher's Note Springer Nature remains neutral with regard to jurisdictional claims in published maps and institutional affiliations. 